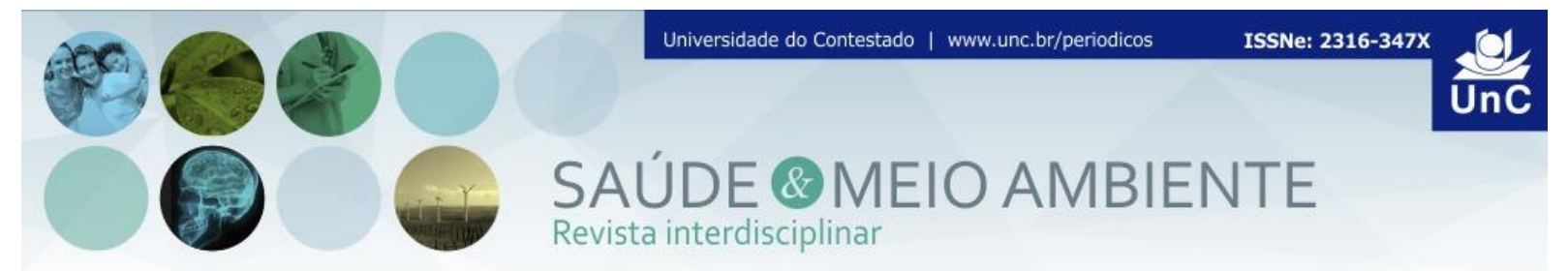

\title{
MEDIDAS PROFILÁTICAS PARA AMENIZAR A QUESTÃO DAS ZOONOSES OCASIONADAS POR CÃES ABANDONADOS NAS RUAS DO BAIRRO FAXINAL, MAFRA - SC ${ }^{1}$
}

\author{
Laís Aline Grossel ${ }^{2}$ \\ Maristela Povaluk ${ }^{3}$
}

\begin{abstract}
RESUMO
Esta pesquisa teve por finalidade principal propor medidas que pudessem ser tomadas para amenizar a questão das zoonoses ocasionadas por cães abandonados nas ruas do Bairro Faxinal - Mafra, SC, além de identificar as causas da grande quantidade de cães nas ruas deste bairro e constatar as prováveis zoonoses que afetam os cães e a população. Foi efetuada pesquisa de campo, com verificação "in loco", para constatar a existência de cães abandonados nas ruas do bairro pesquisado. Estes cães foram registrados fotograficamente através de fichas de observação com dados relacionados à data, horário, local e condições nas quais estes se encontravam. Os roteiros de entrevista foram aplicados às Agentes Comunitárias de Saúde da comunidade, a uma coordenadora de Abrigo de Cães e um veterinário, com questões relacionadas à temática. Foram aplicados questionários para $10 \%$ da comunidade do bairro. Constatou-se que $81 \%$ dos entrevistados possuem cães e destes, $26 \%$ permitem que transitem entre a rua e a residência, o que esclarece que nem todos os cães nas ruas do bairro estão de fato abandonados. Constatou-se que $56 \%$ do público alvo não conhecem as zoonoses e um terço da população entrevistada já contraiu alguma zoonose, sendo as mais comuns a tungíase e dermatites. $36 \%$ da amostragem afirmou já ter sido mordida ou conhecer algum parente ou vizinho que foi mordido por cães que estavam na rua, sendo que alguns inclusive possuíam tutor. Indagados à respeito da responsabilidade por estes animais, $90 \%$ afirmou creditá-la à população e apenas $4 \%$ relatou que se deve à prefeitura. Após a análise dos dados obtidos, efetuou-se uma pesquisa ação, realizada com a distribuição de folders para a comunidade do Bairro Faxinal. Estes continham informações a respeito das principais zoonoses, medidas profiláticas, legislação referentes ao abandono e maus-tratos e atitudes que devam ser tomadas quando presenciados tais crimes. Esta pesquisa foi de grande relevância para a comunidade do bairro, pois propôs maior bem-estar tanto dos cães como da população. A pesquisa buscou oferecer às famílias maiores informações a respeito das zoonoses e formas de preveni-las, além de zelar pela saúde dos cães, animais tão queridos e importantes no convívio social.
\end{abstract}

Palavras chave: Cães. Zoonoses. Medidas profiláticas.

\footnotetext{
${ }^{1}$ Artigo elaborado a partir da pesquisa: Medidas profiláticas para amenizar a questão das zoonoses ocasionadas por cães abandonados nas ruas do bairro faxinal, Mafra - SC

${ }^{2}$ Acadêmica do Curso de Ciências Biológicas - Universidade do Contestado - Campus Universitário de Mafra. Santa Catarina. Brasil. E-mail: lais alineg@hotmail.com

${ }^{3}$ Professora Orientadora da UnC - Universidade do Contestado - Campus Universitário de Mafra. Mestre em Educação: Ensino Superior - FURB, doutora pela PUC/PR. Santa Catarina. Brasil. Email: maristela@unc.br
} 


\begin{abstract}
This research aimed to propose measures that could be taken to alleviate the issue of zoonoses caused by abandoned dogs in Faxinal Subdivision streets - Mafra, SC, in addition to identifying the causes of the large number of dogs on the streets of this neighborhood and find the likely zoonoses that affect dogs and people. Field search was conducted, with verification "in loco", to find the existence of abandoned dogs on the streets of the neighborhood searched. These dogs were recorded photographically through observation forms related to date, time, location and conditions under which they were. The interview scripts were applied with Community Health Agents, a coordinator of Dogs shelter and a veterinarian, with issues related to the theme. Questionnaires were applied to $10 \%$ of the neighborhood community. It was found that $81 \%$ of respondents have dogs and of these $26 \%$ allow these transit between the street and the house, which clarifies that not all dogs in the neighborhood streets are in fact abandoned. It was found that $56 \%$ of the sample do not know the zoonoses and one third of the interviewed population has contracted some zoonosis, being the most common tuangiasis and dermatitis. $36 \%$ of said sampling have been bitten by dogs that were in the street, and some even had owner. When asked about the responsibility for these animals, $90 \%$ said crediting it to the population and only $4 \%$ reported that due to the city hall. After analyzing the data, we performed an action research. This was done with brochures distribution to the community of Faxinal Subdivision. These contained information about the main zoonoses, prophylactic measures, legislation related to the abandonment and illtreatment and attitudes to be taken when witnessed such crimes. This research was of great importance to the community of the neighborhood, as sought greater welfare of the dogs as much of the population. The research sought to offer families more information about zoonoses and ways to prevent them, and care for the health of dogs, animals so dear and important in social life.
\end{abstract}

Key words: Dogs. Zoonoses. Prophylactic measures.

\title{
INTRODUÇÃO
}

Cães e outros animais são comuns vivendo nos lares brasileiros, sendo considerados muitas vezes membros da família, são tratados com zelo e carinho, têm uma casinha para descansar à noite, comida e água à disposição.

Entretanto, é significativa a quantidade de cachorros vivendo abandonados nas ruas das cidades, sobrevivendo de restos de alimentos que os moradores thes cedem ou que encontram revirando sacos de lixo. Portadores de diversas doenças adquiridas na rua, sofrem sem nenhum tratamento. E a situação tende a piorar quando novos filhotes já nascem fadados a viver nas mesmas condições.

Grande é o risco que a população sofre, mantendo contato com tais animais enfermos, pois eles são hospedeiros e transmissores de diversas doenças que 
acometem as pessoas. Até mesmo os animais domésticos, entrando em contato com os animais de rua, podem transmitir graves doenças aos seus donos.

Sendo assim, esta pesquisa teve por finalidade, propor medidas que pudessem ser tomadas para amenizar a questão das zoonoses ocasionadas por cães abandonados nas ruas do bairro Faxinal em Mafra, SC, além de identificar as causas da grande quantidade de cães nas ruas deste bairro e constatar as prováveis zoonoses que afetam os cães e a população.

\section{O CÃO DESDE OS PRIMÓRDIOS}

Análises de DNA confirmam que o cão doméstico (Canis familiaris) teve como ancestral o lobo cinzento (Canis lupus). O que permanece desconhecido é se o cão se originou da seleção natural de lobos que se aproximavam das pequenas populações humanas para se alimentar de restos de comida ou se a separação de lobo e cão ocorreu antes do contato com os humanos (GERGER; ROSSI, 2011).

\footnotetext{
Descobertas arqueológicas evidenciam a existência de contato entre homem e cão há pelo menos quinze mil anos, uma vez que mostraram cães enterrados com seres humanos em posições que sugeriam afetividade entre eles (GERGER; ROSSI, 2011, p. 347).
}

A relação íntima entre homem e cão permitiu o desenvolvimento da capacidade de comunicação entre ambos. Experimentos recentes realizados com cães e lobos indicam que os primeiros têm mais facilidade para compreender gestos feitos pelas pessoas, além de prestarem mais atenção nos rostos humanos. O cão pôde se adaptar bem à convivência com o ser humano, enquanto o lobo sobrevive melhor em habitat selvagem (GERGER; ROSSI, 2011).

\section{O CÃO NOS DIAS ATUAIS}

Evidências apontam os benefícios da interação homem-animal, produzindo efeitos psicológicos, fisiológicos e sociais, como diminuição de estresse e ansiedade, melhora do humor, menor frequência cardíaca e pressão arterial, estímulo a atividades físicas e maior socialização de crianças, idosos e deficientes, além de melhora no aprendizado (SANTANA; OLIVEIRA, 2006).

A relação existente entre cão e ser humano deve estar baseada na "guarda responsável", que se caracteriza pela condição na qual o tutor de um animal se compromete a atender as necessidades físicas, psicológicas e ambientais dele, bem como prevenir os riscos que possa causar à comunidade e ao ambiente. A falta de observação dos princípios da guarda responsável acarreta em diversos problemas, 
entre eles a compra impulsiva associada à inexistência de vínculo afetivo, o que por sua vez pode resultar no abandono do animal (SANTANA; OLIVEIRA, 2006).

Como consequência do abandono tem-se o crescente aumento populacional de "vira-latas", que se reproduzem de forma acelerada e passam a vagar errantes pelas ruas das grandes cidades. Esta superpopulação de animais está exposta a diversas zoonoses, constituindo um problema de saúde pública (SANTANA; OLIVEIRA, 2006).

\section{ZOONOSES}

O aumento de doenças entre a população humana geralmente está relacionada às condições adversas de vida, associadas à degradação do ambiente. A disseminação de doenças ocorre com maior frequência em áreas de grande contingente populacional e sem condições adequadas de higiene e saneamento básico (LIMA et al., 2010).

A substituição gradativa de edificações unifamiliares por edificações multifamiliares sobrecarrega a infraestrutura existente e o lançamento de esgoto e lixo nos corpos d'água, contribuindo para a poluição hídrica e a disseminação de doenças, entre elas as de caráter zoonótico (LIMA et al., 2010, p. 1458).

Existe ainda a questão da relação cada vez mais intensa entre homem e animal, onde este é parte integrante e de igual importância na constituição familiar. Não permanecendo apenas no ambiente doméstico, estes animais, ao transitarem em áreas públicas, com ou sem a presença de seus tutores, depositam seus dejetos em locais de grande movimentação, o que favorece a disseminação de parasitas presentes em fezes e urina, favorecendo o aumento no número de zoonoses (LIMA et al., 2010).

De acordo com a Organização Mundial da Saúde (2016) zoonose é qualquer doença ou infecção naturalmente transmissível de animais vertebrados para o ser humano ou vice versa, podendo ser de origem bacteriana, viral ou parasitária e envolvendo ou não agentes convencionais.

As zoonoses podem ser transmitidas para o ser humano através de mordidas, arranhões e manipulação de excrementos dos animais (GEFFREY; PARIS, 2001 apud LAGES, 2009) sendo que os grupos mais acometidos são crianças, idosos, gestantes e imunossuprimidos (LAGES, 2009).

Medidas simples baseadas na guarda responsável dos animais são de grande importância para reduzir a incidência destas doenças, pois quanto mais queridos e próximos forem os animais de estimação, menores serão as probabilidades de transmitirem zoonoses às pessoas, visto que, quando existe uma relação afetiva íntima entre ambos, os tutores zelam pela higiene e saúde de seus animais, 
prevenindo a transmissão de doenças entre eles (MINISTÉRIO PÚBLICO DE MINAS GERAIS et al., 2013).

\section{MATERIAIS E MÉTODOS}

A presente pesquisa foi efetuada através de pesquisa bibliográfica, pesquisa de campo; por meio de verificação "in loco" e pesquisa ação, tendo como base o método qualitativo e quantitativo. O local utilizado para efetuar a presente pesquisa foi o bairro Faxinal, em Mafra, SC. A amostra foi constituída de 74 cães observados transitando pelas ruas do bairro (alguns avistados em mais de uma ocasião), 10\% das famílias da comunidade, quatro Agentes Comunitárias de Saúde (ACS) que trabalham neste bairro, uma coordenadora de ONG que resgata cães abandonados e um veterinário. A pesquisa foi efetuada entre os meses de janeiro de 2014 e maio de 2015.

A pesquisa de campo foi efetuada através da observação de cães errantes nas ruas do bairro e as condições nas quais se encontravam, através do preenchimento de fichas de observação e registros fotográficos. Foram aplicados questionários com $10 \%$ das famílias do bairro, para verificar seus conhecimentos a respeito de zoonoses e condições à que submetem seus cães. Roteiros de entrevista foram aplicados às Agentes Comunitárias de Saúde, com o intuito de conhecer suas principais dificuldades em relação aos cães errantes que encontram nas ruas onde trabalham. Foram enviados via email, questionários para uma coordenadora de ONG, a fim de compreender como funciona o Abrigo de Cães e o sistema utilizado para posterior adoção dos mesmos; e para um veterinário, que expôs as principais zoonoses observadas nos cães atendidos. Após a análise dos resultados obtidos com as entrevistas, a pesquisa ação foi efetuada com a elaboração de folders para distribuição à comunidade. Estes folders contêm informações a respeito das principais zoonoses, medidas profiláticas, legislação referentes ao abandono e maus-tratos e atitudes que devam ser tomadas quando presenciados tais crimes.

\section{RESULTADOS E DISCUSSÕES}

Não sendo possível caracterizar com precisão as doenças que os cães errantes observados portavam, foram observadas particularidades dos animais, que remetem a alguma enfermidade ou parasitose. Alguns cães foram observados se coçando (provável presença de ectoparasitas) e mancando; com perda de pelos ou crostas em alguma região do corpo (podendo tratar-se de alguma dermatite); urinando em diversos locais ao longo do trecho em que foram observados; revirando sacos de lixo, contendo inclusive, fezes humanas, e bebendo água de valetas e poças d'água; alimentando-se de restos de alimentos deixados por caminhoneiros 
Medidas profiláticas para amenizar a questão das zoonoses ocasionadas por cães abandonados nas ruas do bairro Faxinal, Mafra - SC

em um pátio de uma empresa; bastante magros e abatidos e em possível período de cio (devido à presença de outros cães ao redor e em posição de acasalamento) (Figura 1).

Alguns animais observados apresentaram-se bastante dóceis e aparentemente saudáveis, além de alguns indivíduos possuírem coleira. Moradores relataram que muitos cães que estão na rua possuem tutores, o que foi constatado posteriormente, quando foi encontrado o mesmo cão, em ocasiões diferentes, na rua e dentro do cercado da residência. Estes animais totalmente dependentes de seus tutores, mas que permanecem fora das residências, desacompanhados, são denominados semi-domiciliados (Pasteur apud Nogueira, 2009). Também foi evidenciado que alguns animais surgem nas residências e são alimentados por moradores que sentem compaixão pelos mesmos. Segundo Pasteur apud Nogueira (2009) estes animais são classificados como comunitários ou de vizinhança, pois não apresentam tutores e transitam livremente pelas ruas, mas dependem de alimentação fornecida pelos moradores.

\section{Outros animais mostraram-se bastante arredios e poucos apresentaram agressividade.}

Fotografia 1 - Cães constatados nas ruas do bairro Faxinal.

Cadela com problemas dermatológicos e que estava prenha e foi adotada por moradora (A); Cães com problemas dermatológicos (B e D); Cão se coçando, com provável presença de ectoparasitas (C); Pesquisadora alimentando cães para observação de suas condições (E,H e K); Restos de cão atropelado na BR $116(\mathrm{~F})$; Filhotes abandonados nas margens da BR $116(\mathrm{G})$; Cães em processo de reprodução (I); Cão com ferimentos na orelha (J); Cão revirando lixo contendo fezes humanas (L).
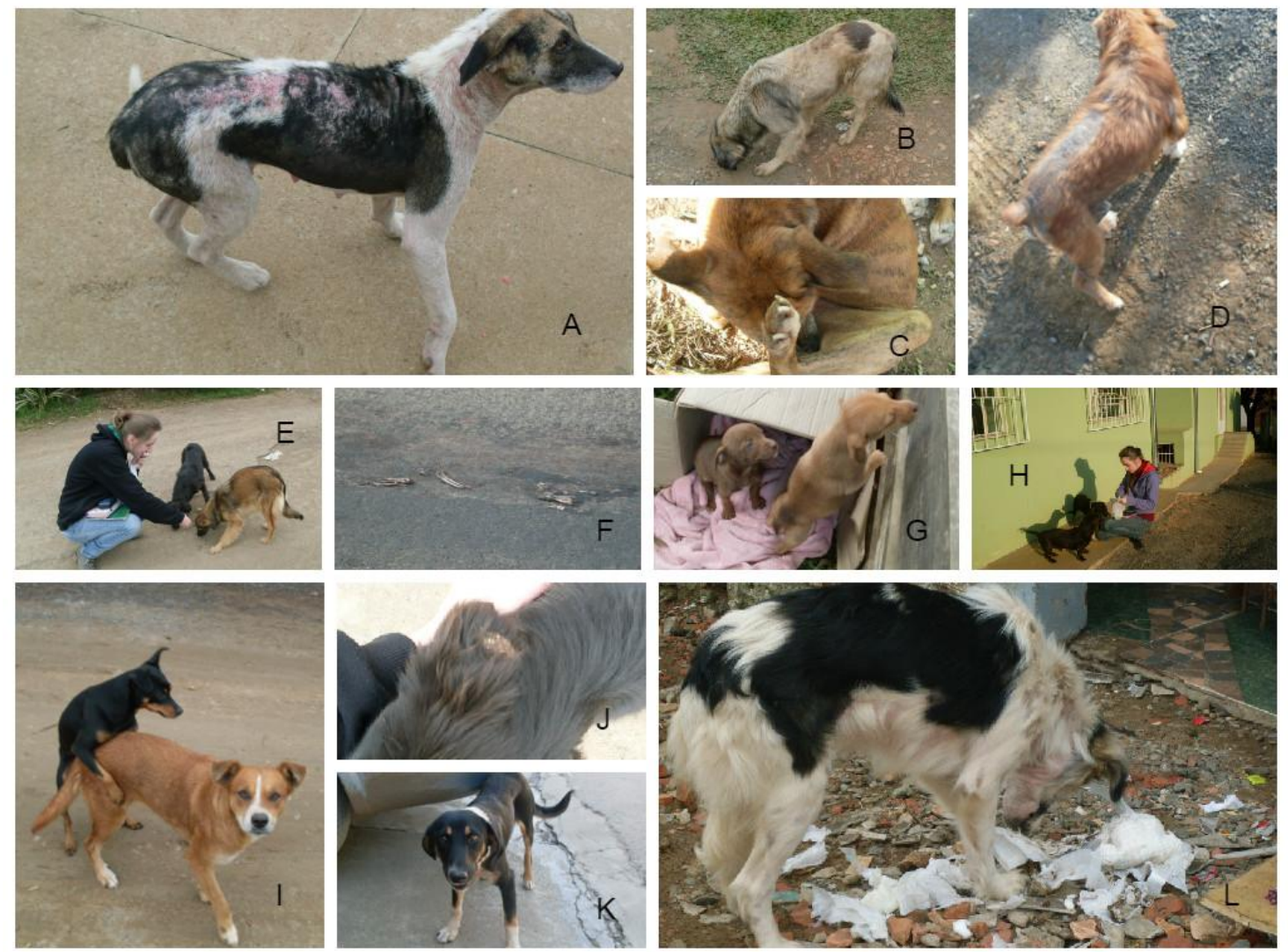

Fonte: Dados da pesquisa, 2015.

Saúde Meio Ambient. v. 5, n. 2, p. 3-20, jul./dez. 2016 
No momento de aplicação de questionários com as ACS, nem todas as áreas do bairro estavam contempladas com o trabalho das mesmas. Geralmente, o quadro é composto por seis Agentes, totalizando em torno de 700 famílias atendidas. Atualmente 536 famílias estão recebendo as visitas das quatro ACS que responderam aos questionários.

Indagadas à respeito do conhecimento com relação a zoonoses, todas afirmaram conhecer o conceito, mas quando solicitado para o definirem apenas duas agentes responderam corretamente.

Tendo sido esclarecido o conceito de zoonose, as ACS foram questionadas sobre terem ouvido algum relato de morador que contraiu alguma zoonose ou parasitose e todas afirmaram já terem presenciado tais situações (sendo as mais comuns dermatites de caráter zoonótico e tungíase). Da mesma forma, quando questionadas sobre a possibilidade de terem contraído alguma delas durante seu trabalho, todas responderam de forma negativa.

Em relação aos cães pesquisados, foi constatado que as quatro agentes observam cães transitando nas ruas em que visitam as famílias, sendo que ainda relataram conhecer a maioria dos cães e saberem que possuem tutor. As agentes também afirmaram que em muitas ocasiões sentem-se ameaçadas por cães agressivos encontrados nas ruas. Uma delas, inclusive já foi atacada por um cão, mas felizmente não foi mordida.

Questionadas sobre a posse de cães em sua residência, todas afirmaram possuir cão, bem como mantê-los dentro do cercado da residência, ou no canil.

Em relação ao questionário com a coordenadora do Abrigo de Cães, a mesma relatou que são recebidos cães em condições extremas de maus-tratos, com fraturas, problemas sérios na pelagem e estado avançado de inanição. Os procedimentos tomados logo após a chegada do cão incluem uma avaliação pelo veterinário voluntário, tratamentos adequados, castração, vacinação e encaminhamento para o Abrigo.

A adoção é incentivada com base na guarda responsável, através de campanhas nas redes sociais e visitas ao abrigo, onde as pessoas podem interagir com os cães. Como explica Lages (2009) a adoção não se trata da distribuição aleatória de animais, mas observação da postura que os novos tutores deverão apresentar para garantir o bem-estar daquele animal, devendo ser realizada com a supervisão dos órgãos públicos, ONGs e profissionais da área.

Segundo o veterinário entrevistado, na clínica onde trabalha as doenças de maior prevalência entre os cães são pneumonia, gastroenterite hemorrágica, cinomose e escabiose (sarna sarcóptica), das quais apenas a escabiose tem caráter zoonótico. Indagado à respeito da existência de vacinas para estas doenças, o veterinário relatou que apenas a escabiose ainda não possui, o que ressalta a importância do uso de medidas para prevenir a transmissão desta entre os cães e destes para os tutores. 
As avaliações, exames e tratamento dos cães resgatados pelo Abrigo de Cães são realizados pelo veterinário, que desenvolve trabalho voluntário nesta ONG.

Questionado à respeito dos benefícios do processo de castração, o veterinário relatou que os animais ficam mais dóceis, além de evitar a reprodução descontrolada. A castração também evita câncer de mama e de ovário nas fêmeas e de próstata e testículo nos machos, infecção uterina, gravidez psicológica, doenças venéreas, entre outras enfermidades. Além disso, o animal tem menor possibilidade de contágio de parasitas, pois se torna mais sossegado e caseiro (MINISTÉRIO PÚBLICO DE MINAS GERAIS et al., 2013).

O veterinário já teve conhecimento de muitos casos de pessoas mordidas por cães de rua, sendo que estas geralmente apresentaram sinais de infecção, inflamação e abscessos na região dos ferimentos.

Quando indagado à respeito de uma medida para diminuição do número de cães nas ruas, o profissional comentou que participa de um projeto de castração de animais de famílias de baixa renda, que não possuem condições para custear o procedimento. Em torno de 300 animais são castrados ao ano, entre machos e fêmeas, sendo que os únicos gastos (com anestesia) são pagos pela prefeitura. Desta forma impede-se que estes animais gerem mais filhotes, que consequentemente serão abandonados nas ruas por estas famílias com condições financeiras limitadas.

As principais dificuldades encontradas na profissão do veterinário, segundo o próprio, estão relacionadas à população que abandona seus animais na clínica, nas ruas ou que deseja a realização de procedimentos de eutanásia em cães saudáveis.

As respostas dos moradores entrevistados foram analisadas e convertidas nos gráficos a seguir.

Questionados sobre a guarda de cães (Gráfico 1), 4 em cada 5 moradores (81\%) responderam que têm um ou mais cães de estimação. Segundo PhillipsDonaldson apud Domingues (2012) sessenta por cento das residências brasileiras possuem pelo menos um animal de estimação. Estas estatísticas colocam o Brasil como o segundo país com maior número de cães e gatos, atrás apenas dos Estados Unidos.

Gráfico 1 - Guarda de cães de estimação nas residências pesquisadas.

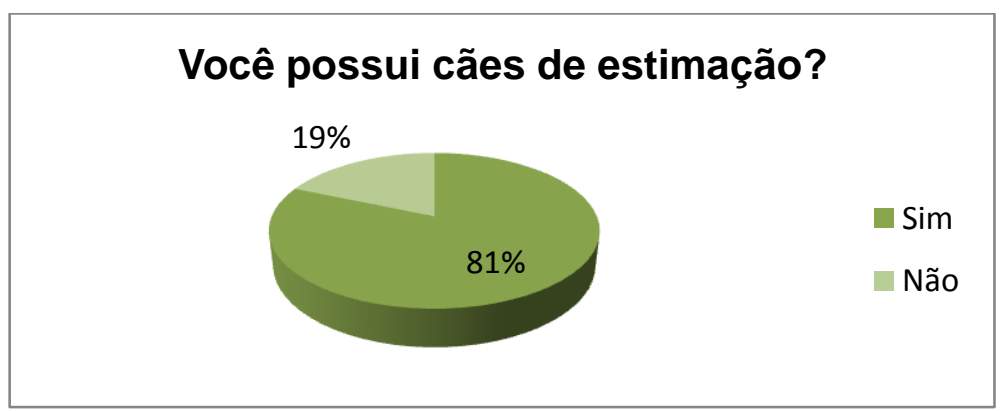

Fonte: Dados da pesquisa, 2015.

Saúde Meio Ambient. v. 5, n. 2, p. 3-20, jul./dez. 2016 
A quantidade de cães mantida pelos moradores (Gráfico 2) variou de 1 a 5 ou mais indivíduos. A maior parte da população (60\%) têm de 2 a 4 indivíduos, sendo que apenas $9 \%$ optou por possuir 5 ou mais cães.

Gráfico 2 - Quantidade de cães nas residências pesquisadas.

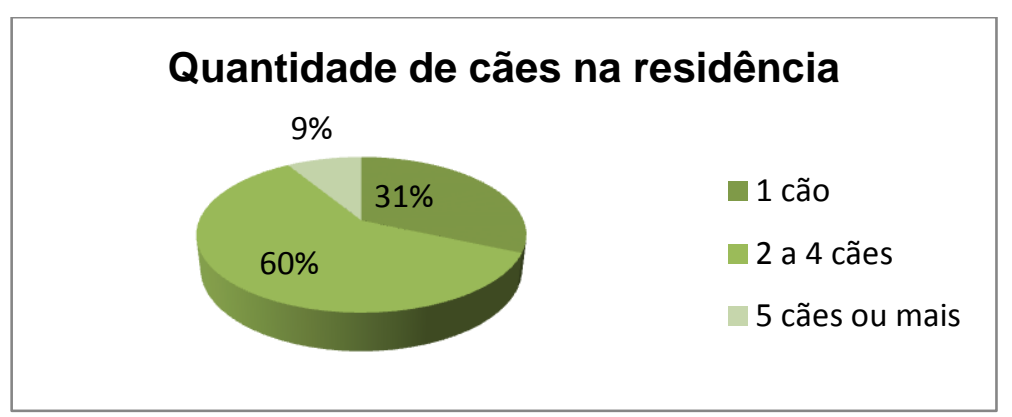

Fonte: Dados da pesquisa, 2015.

Dados preocupantes foram obtidos ao constatar que $1 / 4$ da população permitem que seus animais tenham livre acesso às vias públicas (Gráfico 3). Desta forma, muitos animais errantes pelas ruas podem não ser abandonados, mas possuírem tutor ciente de que não permanecem na residência. Silvano et al., (2010) também constataram em sua pesquisa muitos cães com livre acesso às ruas, sem identificação, e que permaneciam dias sem retornar à residência, ou apresentavam lesões dermatológicas devido à brigas e exposições a ectoparasitas, além de gravidez indesejada. Lages (2009) encontrou resultados semelhantes em relação à porcentagem de moradores que permitem o livre acesso de seus animais às ruas.

Gráfico 3 - Animais que transitam entre a rua e as residências do bairro pesquisado.

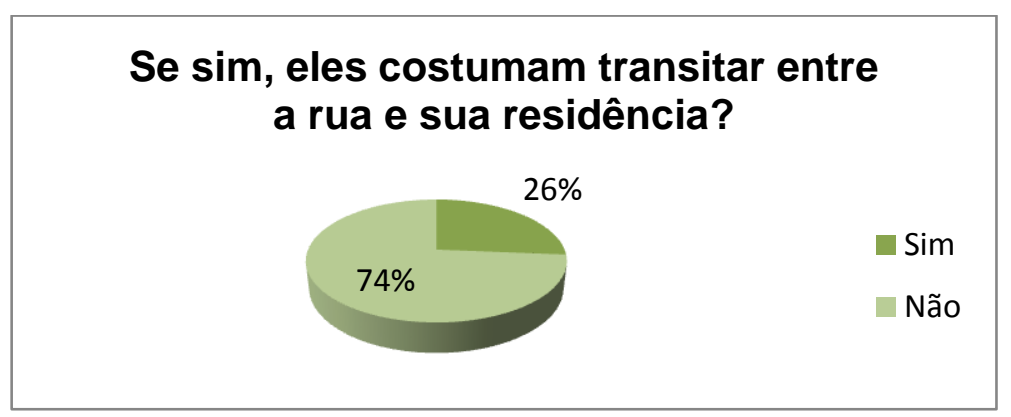

Fonte: Dados da pesquisa, 2015.

Além dos dados que foram obtidos com a entrevista, vários moradores relataram conhecer animais que transitavam pela rua, aparentemente abandonados, citando inclusive seus respectivos tutores. 
Evidenciou-se que 56\% da amostragem (Gráfico 4) não têm conhecimento das doenças que os animais, neste caso os cães, podem transmitir. $44 \%$ dos entrevistados afirmaram conhecer estas doenças e quando indagados sobre quais seriam, relataram principalmente, a raiva e dermatites de caráter zoonótico. Lima et al. (2010) e Sampaio (2014) também constataram que a zoonose mais conhecida pela população é a raiva. Entretanto têm-se uma gama muito mais ampla de doenças que podem ser transmitidas aos tutores e até mesmo aos que não possuem animais de estimação, e que não são do conhecimento dos moradores do bairro. Lages (2009) recomenda ações educativas desenvolvidas em todas as classes sociais dos municípios, com abordagem sobre zoonoses e guarda responsável, pois também constatou desconhecimento de parte da população nesta temática.

Gráfico 4 - Conhecimento do público alvo com relação às zoonoses de transmissão canina.

\section{Você tem conhecimento das doenças que os cães de rua podem transmitir?}

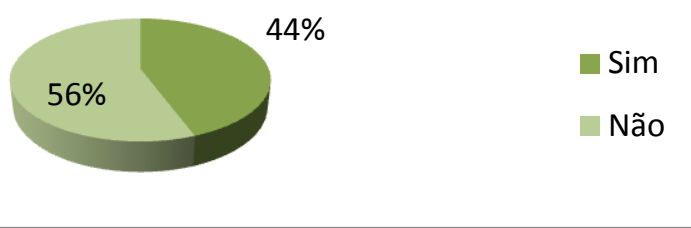

Fonte: Dados da pesquisa, 2015.

Questionados à respeito de algum indivíduo da família ter contraído algum doença de caráter zoonótico (Gráfico 5 ), quase $1 / 3$ da população respondeu de forma afirmativa. Lima et al. (2010) constatou em sua pesquisa que $29,6 \%$ dos entrevistados haviam adquirido ou conheciam alguém que havia contraído alguma zoonose.

Gráfico 5 - Prevalência de zoonoses contraídas pela população.

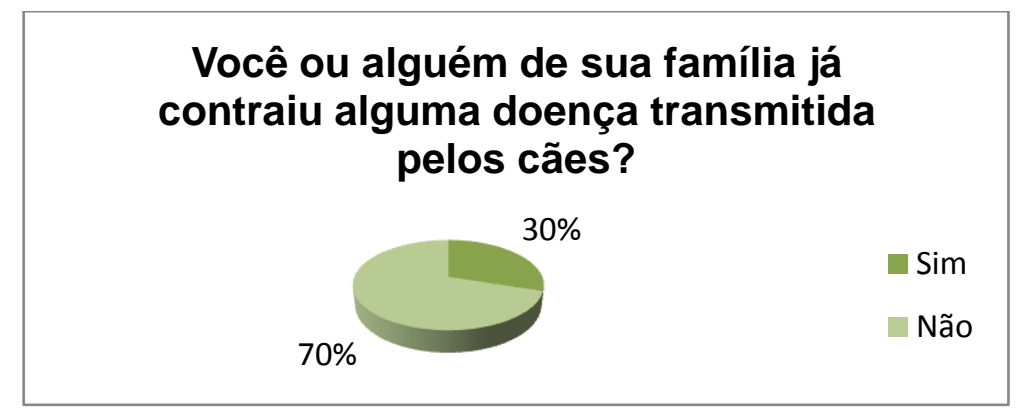

Fonte: Dados da pesquisa, 2015. 
Segundo Lima et al. (2010) as dermatopatias zoonóticas mais comuns na população são a larva migrans cutânea, a sarna e a tungíase. Questionado sobre as zoonoses contraídas ou ectoparasitas com capacidade de transmissão de zoonoses, o público alvo relatou com maior frequência a tungíase (35\%) e dermatites de caráter zoonótico (23\%) (Gráfico 6). Entretanto também foram citadas as micoses de caráter zoonótico (12\%) e a larva migrans cutânea (12\%), conhecida popularmente como bicho geográfico.

Em relação às pulgas, algumas espécies são comumente encontradas no homem e nos animais, provocando infestações mistas, como a cosmopolita Ctenocephalides felis felis e podem transmitir importantes agentes etiológicos. (LIMONGI et al., 2013). Portanto, tanto o cão como o ser humano podem atuar como hospedeiros das pulgas, mas são estas as responsáveis pela transmissão de zoonoses ao ser humano. Entretanto, é necessário levar em consideração que a existência de um animal doméstico aumenta a incidência de infestação por pulgas e riscos de transmissão de zoonoses ao ser humano.

Gráfico 6 - Principais zoonoses ou parasitas contraídos pela população.

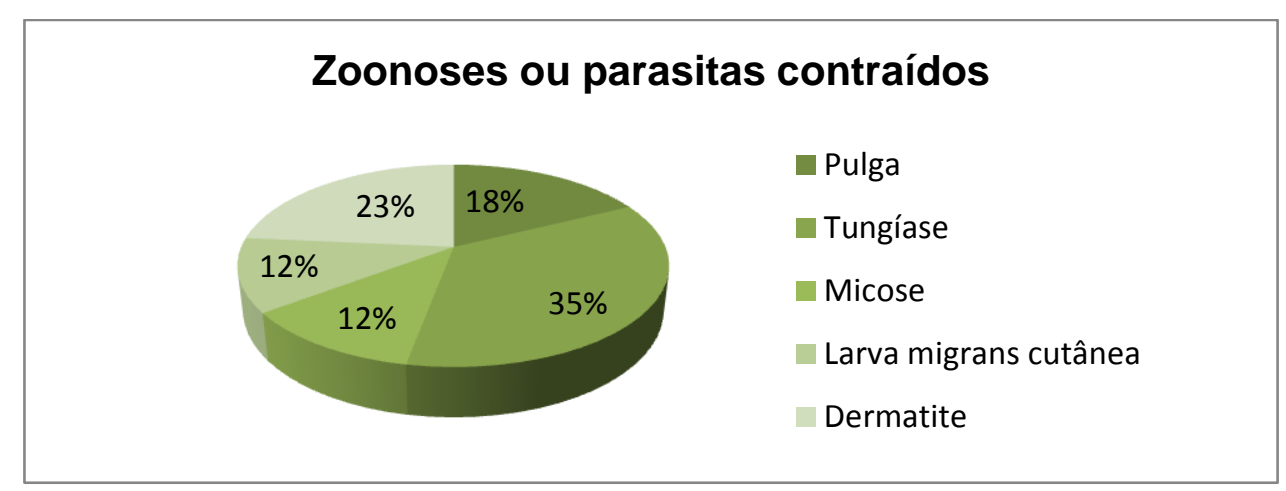

Fonte: Dados da pesquisa, 2015.

Um dos principais receios demonstrado pelos moradores foi a possibilidade de serem mordidos pelos cães que transitam nas ruas do bairro (Gráfico 7). Os relatos de mordidas foram vários, ocorridos com o próprio morador, com algum familiar ou vizinho. O pronto atendimento não foi procurado em todos os casos, 0 que é bastante preocupante. Alguns cães responsáveis pelo ato possuíam tutor, mas estavam soltos pelas ruas. Lages (2009) também constatou que os incômodos mais citados pela população em relação aos animais transitando pelas ruas são medo e dó do animal. 
Gráfico 7 - Moradores ou pessoas próximas mordidos por cães na rua.

Você ou alguém de sua família já

foi mordido por um cão de rua?

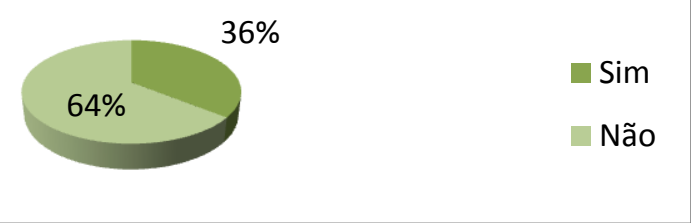

Fonte: Dados da pesquisa, 2015.

Foram relatados casos de moradores que perderam o direito de transitar livremente pela rua devido à agressividade de cães errantes, ou que foram mordidos enquanto passavam pela rua andando de bicicleta ou moto. Teixeira; Halla apud Moutinho; Nascimento; Paixão (2015) constataram em uma comunidade de Canoas, RS, grande problema com cães errantes que agrediam e constrangiam os transeuntes e se envolviam em acidentes de trânsito.

Em relação à grande quantidade de cães transitando pelo bairro, $90 \%$ dos entrevistados (Gráfico 8) credita a responsabilidade aos próprios moradores que possuem animais e devem mantê-los dentro do cercado da residência, castrá-los (caso não deseje que se reproduzam), vaciná-los e evitar abandono de filhotes ou cães idosos e doentes. Estes dados foram importantes para demonstrar a consciência da população à respeito desta questão. Segundo Truppel; Truppel (2009), Código Civil Francês é o ponto inicial de todas as legislações. O art. 1.385 discorre: "O proprietário de um animal, ou aquele que dele se serve, é responsável pelo dano que ele cause, esteja o animal sob sua guarda, tenha-se extraviado ou escapado". O Novo Código Civil Brasileiro, no art. 936 dispõe: "O dono, ou detentor, do animal ressarcirá o dano por este causado, se não prova culpa da vítima ou força maior." Desta forma os tutores de cães que transitam livremente pelas ruas do bairro são totalmente responsáveis por eles e estão sujeitos à indenizar transeuntes ou moradores que sejam agredidos por estes animais.

$4 \%$ dos entrevistados acredita que a solução cabe à prefeitura, que deveria ser responsável por projetos que controlassem a natalidade destes animais, principalmente daqueles que de fato estão abandonados. Outros $4 \%$ afirmam que seria necessária uma parceria entre prefeitura e população para a diminuição dos cães nas ruas. De acordo com Moutinho; Nascimento; Paixão (2015) a responsabilidade pelos cães não domiciliados deve ser interdisciplinar, envolvendo tanto a sociedade como o Poder Público. 
Gráfico 8 - Responsabilidade pelos cães na rua.

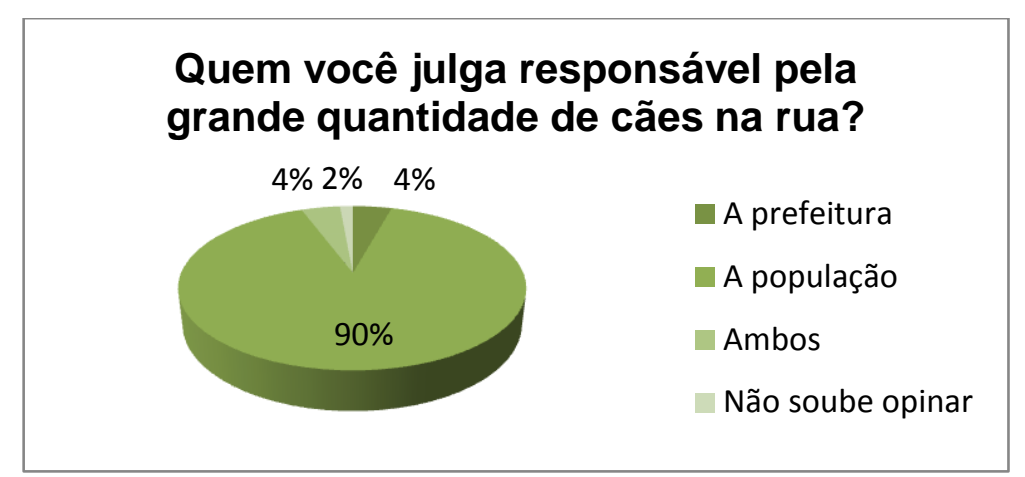

Fonte: Dados da pesquisa, 2015.

Para compreender as causas dos elevados números de cães abandonados nas ruas, os moradores foram questionados à respeito de já terem abandonado ou presenciado o abandono de algum cão (Gráfico 9).

Nenhum morador relatou ter abandonado algum cão na rua, mas 34\% afirmaram já terem presenciado ou encontrado algum cão abandonado próximo à sua residência. Alguns animais foram abandonados dentro do cercado da residência de moradores, ou nas margens da rodovia BR 116. Houve relatos frequentes de moradores que viram veículos, durante à noite, trazendo grandes quantidade de cães e abandonando em ruas menos movimentadas do bairro. Nestes casos, os moradores foram informados em relação à Lei de Crimes Ambientais, nº 9.605/1998, art. 32, que protege os animais de maus-tratos e abandonos, e orientados a anotar as placas dos veículos, para posterior denúncia nos órgãos públicos. O abandono de um animal configura ato de abuso, pois ele fica desamparado e é privado de cuidados básicos.

$17 \%$ dos moradores relataram que adotaram um cão de rua encontrado próximo à sua residência, na maioria dos casos, em péssimas condições (doentes, magros), e motivados pelo sentimento de dó do animal, como também foi observado por Lages (2009). Estes animais foram submetidos à tratamentos adequados e alimentação equilibrada e atualmente estão saudáveis.

Gráfico 9 - Abandonos presenciados pelos moradores.

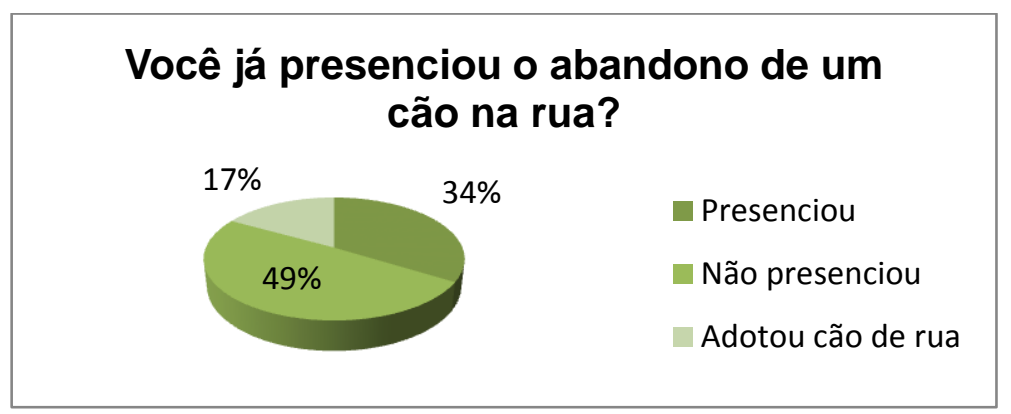

Fonte: Dados da pesquisa, 2015. 
Medidas profiláticas para amenizar a questão das zoonoses ocasionadas por cães abandonados nas ruas do bairro Faxinal, Mafra - SC

A questão № 10 do questionário aplicado aos moradores consistiu em uma sugestão ou ideia que pudesse contribuir para a diminuição de cães transitando pelas ruas (Gráfico 10).

Constatou-se que a sugestão com maior percentual de adeptos (23\%) consiste na conscientização e sensibilização de cada membro da sociedade para a importância da guarda responsável. Vários aspectos estão envolvidos nesta guarda, visto que não se trata de um objeto, mas de um ser vivo, que apresenta necessidades físicas e mentais (SILVANO et al., 2010). Segundo o Ministério Público de Minas Gerais et al. (2013), cientistas em Cambridge declararam recentemente que os animais são seres sencientes, o que significa que possuem consciência de si e são capazes de sentir dor, aspectos provavelmente já observados por tutores dedicados a promover o bem-estar de seus animais de estimação.

Outra parcela dos entrevistados (20\%) acredita que tais animais abandonados devem ser recolhidos por abrigos e posteriormente encaminhados para adoção. Infelizmente o único abrigo existente na cidade está com sua capacidade lotada e não dispõe de recursos financeiros necessários para manter um número maior de animais. Outra sugestão levantada foi a de projetos que criem mais abrigos $(10 \%)$ na região. Sabe-se, entretanto, que tais abrigos são Organizações sem fins lucrativos (ONGs) e não recebem apoio financeiro dos governos municipais e federais. Além disso, atividades isoladas de recolhimento e eliminação de animais errantes não são efetivas para o controle da população. Deve-se atuar na causa do problema, a procriação sem controle e a falta de responsabilidade humana na guarda responsável (OMS apud DOMINGUES, 2011).

Os moradores também sugeriram procedimentos de castração (16\%), e vacinação (17\%) destes animais. Nos casos da esterilização, o Estado deve estabelecer valores acessíveis para o custeio do procedimento, a fim de que mesmo os cidadãos mais humildes possam encaminhar seus animais para realizá-lo, como foi citado pelo veterinário entrevistado. Em relação à vacinação, também cabe ao Estado a realização de campanhas que a incentivem e aproveitem para sensibilizar a população para a guarda responsável e relação de bem-estar entre o animal e o ser humano (SANTANA; OLIVEIRA, 2006).

Outro aspecto salientado foi a implantação de multas (5\%) para tutores que permitem o livre acesso de seus animais à rua, sugestão também constatada por Lages (2009). Para tanto há necessidade de cadastramento de cada animal, com sua identificação (microchipagem) e respectivo tutor, a fim de direcionar as cobranças de taxas para aqueles que se recusem à cumprir seus deveres como tutores responsáveis. O registro destes animais deve ser realizado pelo Poder Público, anualmente, com informações individualizadas dos cães (SANTANA; OLIVEIRA, 2006).

Também foi citado o incentivo à adoção de cães abandonados ou filhotes ao invés de altos custos com animais de raça (4\%). Sobre esta temática, o Ministério Público de Minas Gerais et al., (2013) não considera "responsável" a compra de um 
cão de raça, de criadores que muitas vezes submetem seus animais à maus-tratos, enquanto há inúmeros cães abandonados que poderiam ser adotados das ruas.

Outras sugestões da comunidade incluem ações públicas (3\%), evitar o abandono, buscando pessoas dispostas à adoção do animal (1\%) e implantação do sistema de carrocinha (1\%), que recolheria animais abandonados, fazendo com que os tutores impeçam que seus cães andem pela rua e sejam levados.

Gráfico 10 - Sugestões dos moradores para diminuição do número de cães transitando na rua.

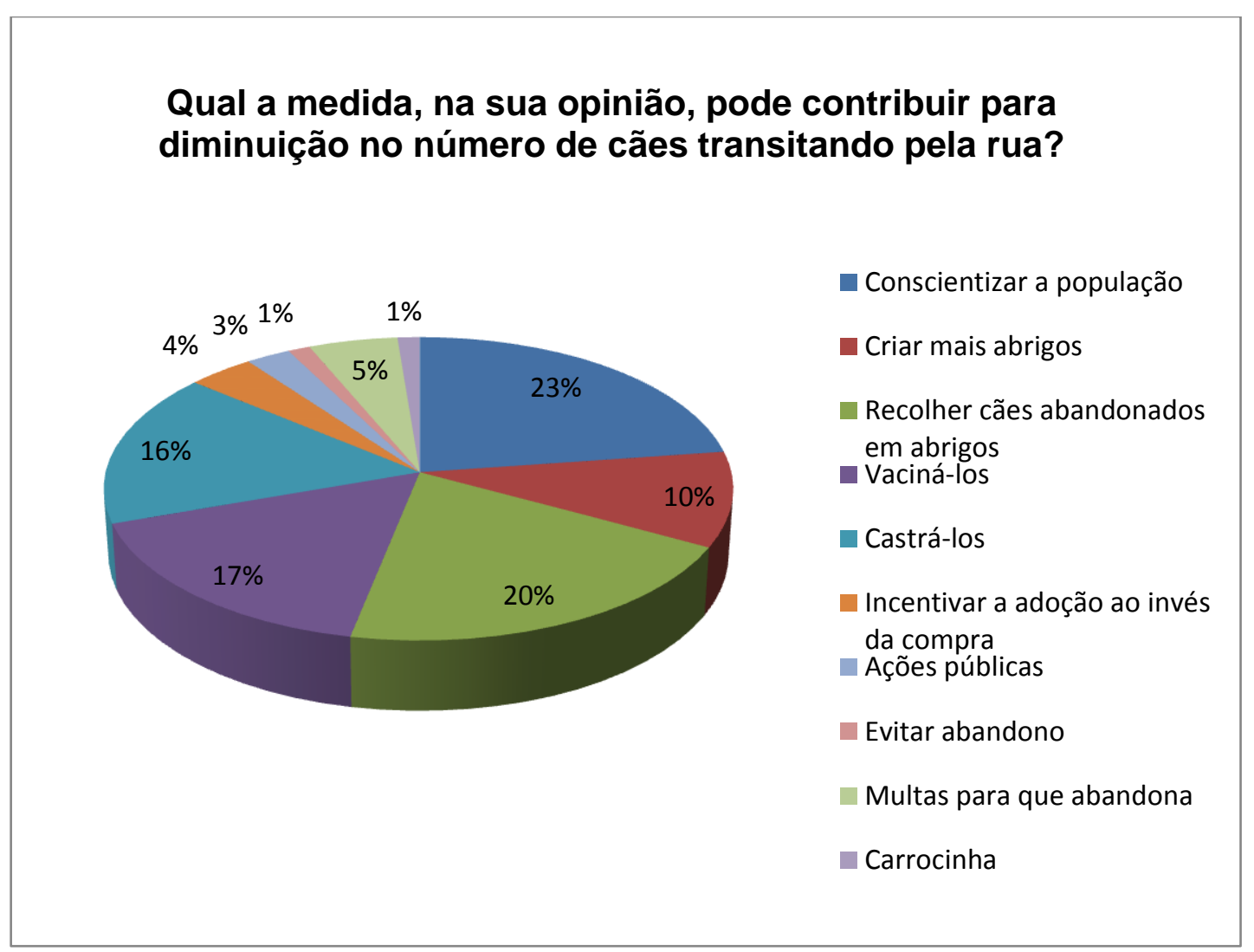

Fonte: Dados da pesquisa, 2015.

Com relação aos instrumentos da Pesquisa Ação, os folders continham informações em relação às principais zoonoses, medidas profiláticas para evitar estas doenças e a Lei Federal de Crimes Ambientais, no 9.605/1998, art. 32, que protege os animais de abuso e maus-tratos.

Em cada residência onde foram encontrados moradores no momento da distribuição dos folders, a pesquisadora explicou de forma sucinta o objetivo da pesquisa e as informações contidas nele, tendo sido recebida com grande interesse. Os moradores que relataram não conhecer as zoonoses ficaram gratos pela informação fornecida e afirmaram que buscariam praticar as medidas profiláticas para maior promoção da saúde de si mesmos, e consequentemente da comunidade do bairro. Silvano et al. (2010) observaram que o desconhecimento da população em relação aos aspectos éticos e morais da guarda responsável não significam descaso ou desafeto, mas comprovação da necessidade de informação sobre a 
temática, como também foi observado na presente pesquisa, em relação ao desconhecimento de parcela da população sobre as zoonoses.

Flores; Drehmer apud Sampaio (2014) citam a educação sanitária como um importante instrumento para a promoção de novas atitudes que possam habilitar a população a resolver seus próprios problemas de saúde. Dos Santos apud Lages (2009) explica que diversos problemas relacionados à saúde animal e pública podem ser minimizados com educação em saúde.

\section{CONSIDERAÇÕES FINAIS}

Com a referida pesquisa, foi constatado que parte dos animais observados pelas ruas do bairro não estão abandonados, mas são semi-domiciliados, pois possuem tutores que permitem seu livre acesso entre a rua e suas residências. $O$ ato de transitar entre estes ambientes permite que os cães entrem em contato com animais infectados, parasitas e patógenos causadores de diversas zoonoses, que poderão ser transmitidas ao tutor do cão e seus familiares.

Alguns cães observados apresentaram dermatites e sinais da presença de ectoparasitas, dados que vêm de encontro às zoonoses contraídas com maior frequência pela população, tungíase e dermatites de caráter zoonótico.

Evidenciou-se que a temática das zoonoses é desconhecida para aproximadamente metade do público alvo. Como forma de fornecer subsídios à população em relação à medidas profiláticas, foi efetuada a entrega de folders para a disseminação de informações básicas, mas que evitam a contaminação e transmissão de doenças entre os cães e zoonoses entre eles e as pessoas. A orientação da população através dos folders reforçou a sugestão apresentada pela própria comunidade, de que a principal medida a ser tomada para a diminuição dos cães transitando pelas ruas, e conseqüente promoção da saúde e bem-estar da população, é a sensibilização de cada morador com a guarda responsável de seu cão, em relação à seus direitos e principalmente deveres para com a sociedade.

Como forma de diminuir as taxas de abandono de cães nas ruas do bairro, o folder também forneceu informações em relação à Lei Federal de Crimes Ambientais, no 9.605/1998, art. 32, que preconiza como crime ambiental atos de abuso e maus-tratos de animais silvestres e domésticos, tendo sido elencados os procedimentos para realização de denúncia anônima. O abandono de animais é considerado ato de abuso, pois estão privados das necessidades básicas, como alimentação e abrigo.

A pesquisa foi fundamental para a compreensão das altas taxas de cães transitando pelo bairro e possíveis doenças que apresentam, podendo ser transmitidas aos seus tutores ou moradores que mantêm contato, quando se tratam de zoonoses. Sobretudo, a pesquisa foi de grande relevância para a comunidade, que recebeu informações importantes sobre as medidas que devem ser tomadas 
para evitar a disseminação de zoonoses e como proceder ao presenciarem situações de abandono de cães, e que estarão contribuindo também, ainda que de forma indireta, para a difusão de práticas de guarda responsável dos cães do Bairro Faxinal, Mafra, SC.

\section{REFERÊNCIAS}

DOMINGUES; Lídice Rodrigues. Posse responsável de cães e gatos na área urbana do município de Pelotas, RS, Brasil. Pelotas: UFPEL, 2012. 87 p. Dissertação (Mestrado em Epidemiologia) - Programa de Pós-Graduação em Epidemiologia, Faculdade de Medicina, Universidade Federal de Pelotas, Pelotas, 2012.

GERGER, Alida; ROSSI, Alexandre. Cão de família: a arte de cuidar, educar e ser feliz com seu melhor amigo. Rio de Janeiro: Agir,

LAGES, Sonia Luisa Silva. Avaliação da população de cães e gatos com proprietário, e do nível de conhecimento sobre a raiva e posse responsável em duas áreas contrastantes de cidade de Jaboticabal, São Paulo. Jaboticabal: Universidade Estadual Paulista "Júlio de Mesquita Filho", 2009, 86 p. Dissertação (Mestrado em Medicina Veterinária Preventiva) - Faculdade de Ciências Agrárias e Veterinárias, Universidade Estadual Paulista "Júlio de Mesquita Filho", Jaboticabal, 2009.

LIMA, Ana Maria Alves et al. Percepção sobre o conhecimento e profilaxia das zoonoses e posse responsável em pais de alunos do pré-escolar de escolas situadas na comunidade localizada no bairro de Dois Irmãos na cidade do Recife (PE). Ciência e Saúde Coletiva, Rio de Janeiro, v. 15, Supl. 1, p. 1457-1464, 2010.

LIMONGI, Jean Ezequiel et al. Aspectos epidemiológicos das infestações por sifonápteros na área urbana do município de Uberlândia, Minas Gerais, 2007-2010. Epidemiologia e Serviços de Saúde, Brasília, v. 22, n. 2, p. 285-294, abr./jun. 2013.

MINAS GERAIS. MINISTÉRIO PÚBLICO. Guarda Responsável: que bicho é esse? Ensinando o respeito à vida e aos direitos dos animais. Belo Horizonte, 2013.

MOUTINHO; Flavio Fernando Batista, NASCIMENTO; Elmiro Rosendo do, PAIXÃO; Rita Leal. Percepção da sociedade sobre a qualidade de vida e o controle populacional de cães não domiciliados. Ciência Animal Brasileira, Goiânia, v. 16, n. 4, p. 574-588, out./dez. 2015.

NOGUEIRA; Fernanda Aleixo. Posse responsável de animais de estimação no bairro da Graúna - Paraty, RJ. Revista Educação Ambiental, BE-597, São Paulo, v. 2, 2009. 
SAMPAIO, Amanda Bisso. Percepção da população do município de Cruz Alta (RS) sobre zoonoses transmitidas por cães e gatos. Acta Veterinaria Brasilica, Rio Grande do Norte, v. 8, n. 3, p. 179-185, 2014.

SANTANA, Luciano Rocha, OLIVEIRA; Thiago Pires. Guarda responsável e dignidade dos animais. Revista Brasileira de Direito Animal, Salvador, v. 1, p. 67104, 2006.

SILVANO, D. et al. Divulgação dos princípios da guarda responsável: uma vertente possível no trabalho de pesquisa a campo. Revista Eletrônica Novo Enfoque, Rio de Janeiro, v. 9, n. 9, p. 64-86, 2010.

TRUPPEL, Michele de Menezes; TRUPPEL, Silvio Francisco Mendes. A responsabilidade civil da guarda de animais no Brasil. Âmbito Jurídico, Rio Grande, XII, no 71, dez. 2009.

World Health Organization. Zoonoses. Disponível em

<http://www.who.int/zoonoses/en/>. Acesso em 11 jul 2016.

Artigo recebido em: 03/04/2015

Artigo aprovado em: 12/11/2016 